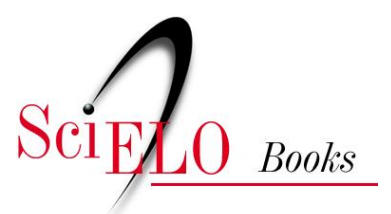

\title{
Ordem Lophiiformes
}

\author{
Ana Cristina Teixeira Bonecker \\ Claudia Akemi Pereira Namiki \\ Márcia Salustiano de Castro \\ Paula Nepomuceno Campos
}

\section{SciELO Books / SciELO Livros / SciELO Libros}

BONECKER, ACT., et al. Ordem Lophiiformes. In Catalogo dos estágios iniciais de desenvolvimento dos peixes da bacia de Campos [online]. Curitiba: Sociedade Brasileira de Zoologia, 2014, pp. 148-152. Zoologia: guias e manuais de identificação series. ISBN 978-85-98203-10-2.

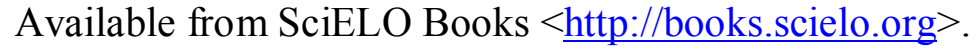

\section{(9)(1)(2)}

All the contents of this chapter, except where otherwise noted, is licensed under a Creative Commons Attribution-Non Commercial-ShareAlike 3.0 Unported.

Todo o conteúdo deste capítulo, exceto quando houver ressalva, é publicado sob a licença Creative Commons Atribuição Uso Não Comercial - Partilha nos Mesmos Termos 3.0 Não adaptada.

Todo el contenido de este capítulo, excepto donde se indique lo contrario, está bajo licencia de la licencia Creative Commons Reconocimento-NoComercial-CompartirIgual 3.0 Unported. 


\section{ORDEM LOPHIIFORMES}

A ordem Lophiiformes é formada por 18 famílias com 313 espécies. São marinhas e a maioria ocorre em águas profundas. Possuem o corpo arredondado ou globular. Nos juvenis e adultos o primeiro espinho dorsal é transformado em um illicium.

Nesse estudo a ordem Lophiiformes é representada pelas famílias Antennariidae e Gigantactinidae. 


\section{Família Antennariidae}

A família Antennariidae é marinha e ocorre em todos os mares tropicais e subtropicais, exceto Mar Mediterrâneo. Compreende 12 gêneros com 42 espécies. Possui o corpo alto ou globoso, boca grande. Pode ser separada das demais famílias de Lophiiformes por possuírem três espinhos dorsais bem desenvolvidos. A nadadeira peitoral é pedunculada.

No Brasil já foram identificadas três espécies nas fases de larva e adulto: Antennarius multiocellatus (Valenciennes, 1837); Antennarius striatus (Shaw \& Nodder, 1794) e Histrio histrio (Linnaeus, 1758). Nesse estudo é contemplada a espécie Histrio histrio. 


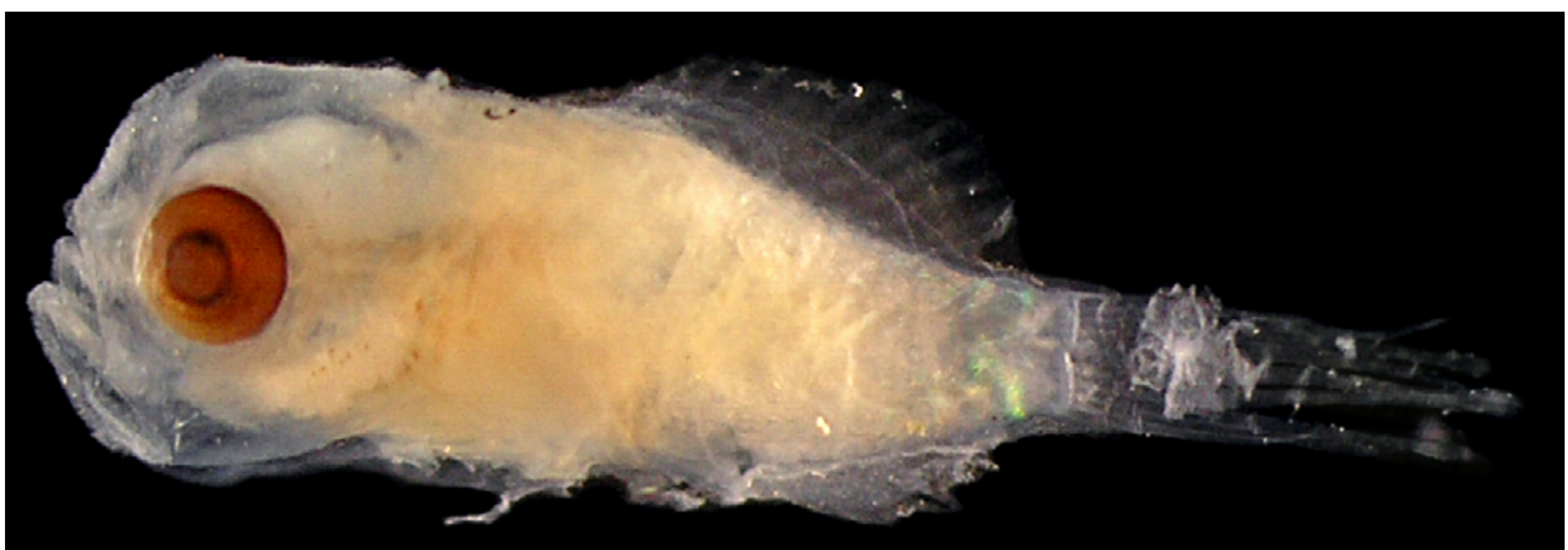

Figura 88: Histrio histrio. DZUFRJ 24179; Flexão; CP 2,7 mm.

\section{Histrio histrio (Linnaeus, 1758)}

A cabeça é grande compreendendo até $50 \%$ do corpo. As larvas menores em pré-flexão e flexão (até $5,0 \mathrm{~mm}$ ) estão envoltas em uma membrana. Pigmentos presentes na cabeça e na região do intestino. Nadadeira peitoral pedunculada. À medida que as larvas crescem a base da nadadeira pélvica cresce também. A nadadeira caudal é a primeira a ser formada, seguida pela dorsal e anal. A dorsal é formada por três espinhos e 11-13 raios e a anal por 6-8 raios. Possui aproximadamente 19 miômeros.

Tamanho: flexão 2,7-3,0 mm.

Habitat: espécie marinha, pelágica, associada a formações coralinas e a Sargassum. Ocorre em águas tropicais e subtropicais até $100 \mathrm{~m}$ de profundidade.

Nome vulgar: Peixe sargasso.

\section{Georreferenciamento}

\begin{tabular}{|c|c|c|c|c|c|c|c|c|}
\hline DZUFR & Latitude (S) & Longitude (W) & Data & $\begin{array}{c}\text { Tipo de } \\
\text { arrasto }\end{array}$ & $\begin{array}{c}\text { Profundidade } \\
\text { de coleta }\end{array}$ & Rede & $\begin{array}{c}\text { Malha } \\
\text { ( } \boldsymbol{\mu m} \text { ) }\end{array}$ & $\begin{array}{c}\mathbf{N}^{\circ} \text {. de } \\
\text { inds. }\end{array}$ \\
\hline 1173 & $22^{\circ} 02^{\prime} 30,3^{\prime \prime}$ & $039^{\circ} 50^{\prime} 41,3^{\prime \prime}$ & $10 / 05 / 2002$ & oblíquo & $1.000 \mathrm{~m}$ & cilíndrico-cônica & 500 & 1 \\
\hline 24179 & $22^{\circ} 31^{\prime} 58,9^{\prime \prime}$ & $040^{\circ} 02^{\prime} 53,4^{\prime \prime}$ & $07 / 11 / 2001$ & oblíquo & $1.000 \mathrm{~m}$ & cilíndrico-cônica & 500 & 1 \\
\hline
\end{tabular}

Referências: Jackson, 2006a; Fahay, 2007. 


\section{Família Gigantactinidae}

A família Gigantactinidae é marinha, mesopelágica e batipelágica. Ocorre nos oceanos Atlântico, Índico e Pacífico. Compreende dois gêneros com 22 espécies. A principal característica para separar essa família dos demais Lophiiformes é a presença de nadadeiras peitorais muito grandes, mesmo nos exemplares bem pequenos, chegando além das inserções das nadadeiras dorsal e anal. Não possuem nadadeiras pélvicas e têm entre 4-10 raios na nadadeira dorsal.

No Brasil já foi identificada uma espécie na fase de adulto: Gigantactis vanhoeffeni Brauer, 1902. Nesse estudo é contemplada a espécie Gigantactis sp. 


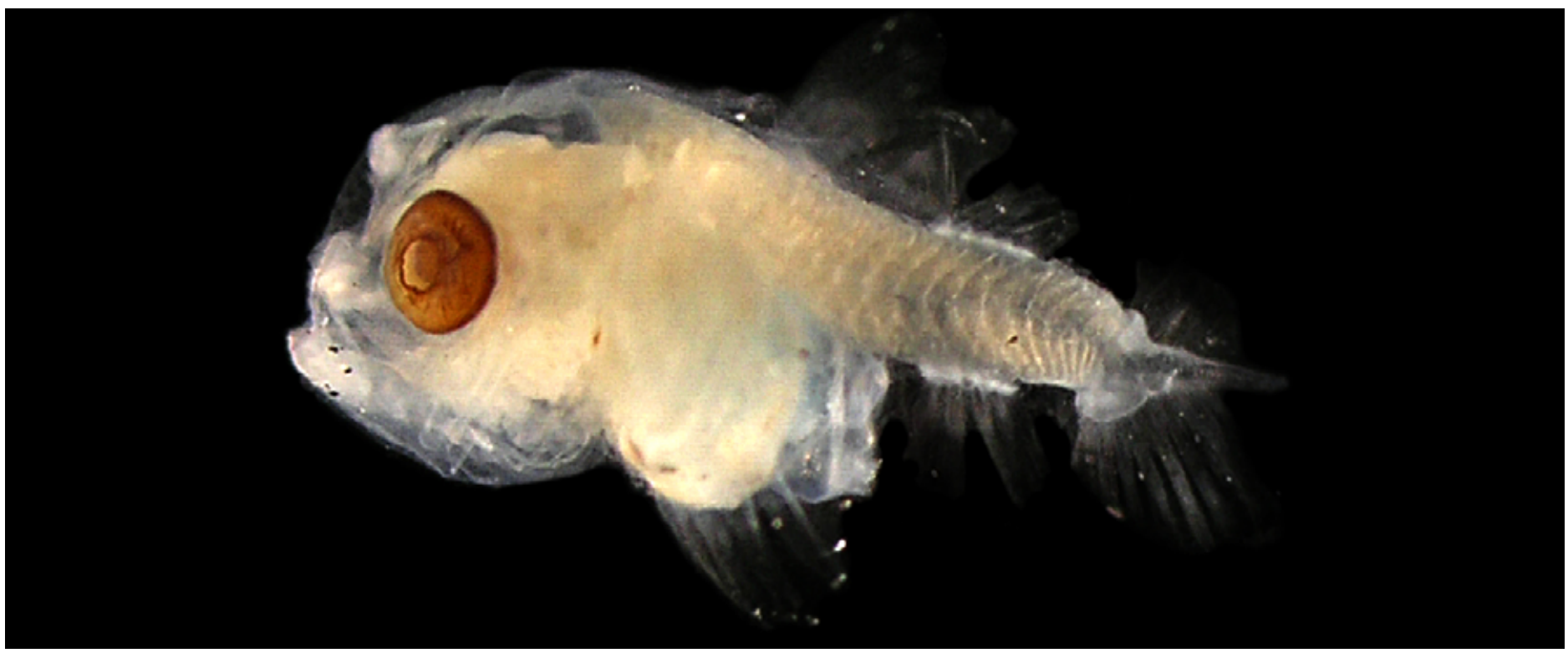

Figura 89: Gigantactis sp. DZUFRJ 1286; Flexão; CP 2,5 mm.

\section{Gigantactis sp.}

O corpo é pequeno (aproximadamente 22 miômeros), muito redondo e apresenta a membrana muito inflada. Nadadeira peitoral muito grande alcançando as bases das nadadeiras dorsal e anal. Não possuem nadadeiras pélvicas e não tem pigmentos no pedúnculo caudal.

Tamanho: flexão $2,5 \mathrm{~m}$.

Habitat: todas as espécies de Gigantactis são marinhas, mesopelágicas e batipelágicas. Ocorrem em águas tropicais e subtropicais e algumas espécies já foram registradas até $5.300 \mathrm{~m}$ de profundidade. Entretanto, a maioria ocorre entre 300 e $1.700 \mathrm{~m}$ de profundidade.

\section{Georreferenciamento}

\begin{tabular}{|c|c|c|c|c|c|c|c|c|}
\hline DZUFR & Latitude (S) & Longitude (W) & Data & $\begin{array}{c}\text { Tipo de } \\
\text { arrasto }\end{array}$ & $\begin{array}{c}\text { Profundida- } \\
\text { de de coleta }\end{array}$ & Rede & $\begin{array}{c}\text { Malha } \\
(\boldsymbol{\mu m})\end{array}$ & $\begin{array}{c}\mathbf{N}^{\circ} \text {. de } \\
\text { inds. }\end{array}$ \\
\hline 1286 & $22^{\circ} 06^{\prime} 52,3^{\prime \prime}$ & $039^{\circ} 48^{\prime} 46,2^{\prime \prime}$ & $11 / 05 / 2002$ & oblíquo & $\begin{array}{c}\text { até a } \\
\text { termoclina }\end{array}$ & bongô & 500 & 1 \\
\hline
\end{tabular}

Referências: Jackson, 2006a; Fahay, 2007. 